\title{
Multitemporal snow cover mapping in mountainous terrain for Landsat climate data record development
}

\author{
Christopher J. Crawford ${ }^{\text {a,* }}$, Steven M. Manson a , Marvin E. Bauer ${ }^{\mathrm{b}}$, Dorothy K. Hall ${ }^{\mathrm{c}}$ \\ a Department of Geography, University of Minnesota-Twin Cities, Minneapolis, MN 55455, United States \\ ${ }^{\mathrm{b}}$ Department of Forest Resources, University of Minnesota-Twin Cities, St. Paul, MN 55108, United States \\ c Cryospheric Sciences Laboratory, Code 615, NASA Goddard Space Flight Center, Greenbelt, MD 20771, United States
}

\section{A R T I C L E I N F O}

\section{Article history:}

Received 16 November 2012

Received in revised form 18 March 2013

Accepted 11 April 2013

Available online 8 May 2013

\section{Keywords:}

Landsat

Multitemporal

Snow cover

Climate data record

Mountains

\begin{abstract}
A B S T R A C T
A multitemporal method to map snow cover in mountainous terrain is proposed to guide Landsat climate data record (CDR) development. The Landsat image archive including MSS, TM, and ETM + imagery was used to construct a prototype Landsat snow cover CDR for the interior northwestern United States. Landsat snow cover CDRs are designed to capture snow-covered area (SCA) variability at discrete bi-monthly intervals that correspond to ground-based snow telemetry (SNOTEL) snow-water-equivalent (SWE) measurements. The June 1 bi-monthly interval was selected for initial CDR development, and was based on peak snowmelt timing for this mountainous region. Fifty-four Landsat images from 1975 to 2011 were preprocessed that included image registration, top-of-the-atmosphere (TOA) reflectance conversion, cloud and shadow masking, and topographic normalization. Snow covered pixels were retrieved using the normalized difference snow index (NDSI) and unsupervised classification, and pixels having greater (less) than 50\% snow cover were classified presence (absence). A normalized SCA equation was derived to independently estimate SCA given missing image coverage and cloud-shadow contamination. Relative frequency maps of missing pixels were assembled to assess whether systematic biases were embedded within this Landsat CDR. Our results suggest that it is possible to confidently estimate historical bi-monthly SCA from partially cloudy Landsat images. This multitemporal method is intended to guide Landsat CDR development for freshwaterscarce regions of the western US to monitor climate-driven changes in mountain snowpack extent.
\end{abstract}

(c) 2013 Elsevier Inc. All rights reserved.

\section{Introduction}

Continental ice sheets, sea ice, permafrost, and hemispheric-scale seasonal snow cover play an important role in regulating the Earth's radiation balance, and poleward-equatorial latent heat transport during hemispheric cool-seasons (Barry, 2002). Equally important, mountain glaciers and seasonal snow cover (extent) in the form of mountain snowpack (depth) feed seasonal streamflow and replenish hydrological catchments (Barnett et al., 2005; Winther \& Hall, 1999). Across the arid western US, mountain ranges serve as seasonal water towers that hold and release snowpack freshwater resources through successive snow accumulation and melt. Snow-fed streamflow contributes approximately $50-70 \%$ to the total western US annual water budget (Cayan, 1996). With an automated temporally discrete snow telemetry (SNOTEL) snow-water-equivalent (SWE) measurement network already in place for hydrological forecasting (Serreze et al., 1999), it is quite clear that spatially-explicit, satellite-derived

\footnotetext{
* Corresponding author at: Department of Geography, University of Minnesota-Twin Cities, 414 Social Sciences, 267 19th Ave. S, Minneapolis, MN 55455, United States. Tel.: + 16126258949 .

E-mail address: crawf188@umn.edu (C.J. Crawford).
}

climate data record (CDR) development can augment western US mountain snow-covered area (SCA) monitoring on past, present, and future timescales.

Evidence is mounting for alarming declines in western US mountain snowpack as well as decreasing Northern Hemisphere spring snow cover extent (Brown \& Robinson, 2011; Derksen \& Brown, 2012; Hamlet et al., 2005; Mote et al., 2005; Pierce et al., 2008). Declining snowpack trends have been linked to warming springtime temperatures that trigger earlier and faster snowmelt (Cayan et al., 2001; Westerling et al., 2006). Knowles et al. (2006) find in their assessment of precipitation-snow ratios that snowpack in lower elevation zones are melting faster with temperature-driven phase changes in water. Therefore, blending spatially derived snow cover CDRs, topographic models, SNOTEL SWE, and instrumental climate observations using time-series analysis techniques could advance efforts to examine historical trends in mountain snowpack extent, but has not been attempted because of lacking satellite CDR availability.

Over the past four decades, optical remote sensing has provided a critically important data source for observing the Earth's changing cryosphere. Multispectral imagery acquired by Advanced Very-High Resolution Radiometer (AVHRR), Moderate Resolution Imaging Spectroradiometer (MODIS), Landsat multispectral scanner system 
(MSS), Landsat Thematic Mapper (TM), and Landsat Enhanced Thematic Mapper Plus (ETM +) platforms at different pixel resolutions enable snow cover retrieval over continental regions. Snow exhibits high-moderately high reflectances at visible wavelengths and low reflectances at near-infrared wavelengths (Warren, 1982; Wiscombe \& Warren, 1980). These spectral characteristics allow for pixel level snow retrieval and classification at acceptable thematic and spatial accuracy (Dozier, 1984; Dozier \& Painter, 2004; Hall \& Martinec, 1985). Specific advantages to monitoring snow cover using satellite platforms include daily-weekly image acquisitions, broad-scale spatial coverage over remote mountain and high latitude regions (Dozier, 1989; Dozier \& Painter, 2004; Hall \& Martinec, 1985; Rosenthal \& Dozier, 1996), and most importantly, the Landsat mission provides a fairly continuous historical image record at recurrent intervals. This paper uses the entire Landsat image archive to map mountain SCA since the 1970s.

A multitemporal method is proposed to guide Landsat snow cover CDR development for freshwater-scarce regions of the western US. Historically, the cost of digital imagery hindered multitemporal mapping and use of partially cloudy images. With a now freely available image archive at the USGS EROS Data Center (http://eros.usgs.gov/) from Landsat's MSS, TM, and ETM + mission, the opportunity to construct CDRs on climatically relevant timescales is now possible without the high cost. On the other hand, raw data availability first requires that sound methods for Landsat CDR development be outlined through a concept description and data demonstration. This initial step ensures that Landsat snow cover CDR products are spatially and temporally accurate, radiometrically consistent, and interoperable with MODIS snow products from the outset (Hall et al., 2002b).

This paper introduces an operational multitemporal method to map SCA in mountainous terrain to support Landsat CDR development. A prototype Landsat snow cover CDR for peak snowmelt is demonstrated for an interior northwestern US sub-region, namely the central Idaho and southwestern Montana mountains. This continental sub-region was selected for its Pacific Ocean influenced climatology, intermountain hydrological basin significance, and high topographic relief within the broader northern Rocky Mountain region. This study region is also motivated by the need for more basic satellite research on continental snow cover patterns and processes in mountainous terrain. The paper is organized as follows. Section two outlines a multitemporal method for snow cover mapping in mountainous terrain using the Landsat image archive. This section describes how Landsat snow cover CDRs are derived using a normalized SCA equation, and assesses whether the prototype Landsat CDR contains systematic biases that arise from missing imagery and/or cloud-shadow contamination. The Landsat snow cover CDR is then evaluated to determine whether scale parameterization influences the probability distribution and time domain variance of SCA. Section three presents the results obtained from the multitemporal method and prototype SCA time-series. Section four discusses current Landsat snow cover CDR development including efforts to monitor climate-driven changes in mountain snowpack extent.

\section{Multitemporal method for Landsat CDR development}

\subsection{Landsat archival imagery and study region description}

Landsat World Reference System (WRS)-1 and WRS-2 path-row image acquisitions over the prototype study region depend on the sensor and year of acquisition (Table 1 ). For this June 1 snow cover CDR, Landsat MSS, TM, ETM + SLC-on, and ETM + SLC-off images were collected during the Julian dates 143 and 158 for 1973-2011. Scan line coverage (SLC) 'on' and 'off' images reflect time periods for 'pre' and 'post' sensor malfunctions on Landsat ETM +. Landsat $\mathrm{ETM}+$ SLC-off images have stripes that contain missing pixels across
Table 1

Archival Landsat imagery used for June 1 snow cover CDR development.

\begin{tabular}{lllll}
\hline $\begin{array}{l}\text { Landsat } \\
\text { sensor }\end{array}$ & $\begin{array}{l}\text { Julian bi-monthly } \\
\text { interval }\end{array}$ & Time period & Path-rows & $\begin{array}{l}\text { Images } \\
\text { used (n) }\end{array}$ \\
\hline MSS 1-3 & $143-158$ & $1973-1983$ & $42-29,43-29$ & 5 \\
MSS 4-5 & $143-158$ & $1982-1995$ & $39-29,40-29$ & 4 \\
TM 4-5 & $143-158$ & $1984-2011$ & $39-29,40-29$ & 33 \\
ETM + 7 SLC-on & $143-158$ & $1999-2003$ & $39-29,40-29$ & 4 \\
ETM + 7 SLC-off & $143-158$ & $2003-2011$ & $39-29,40-29$ & 8 \\
\hline
\end{tabular}

the image. SLC-off pixels have no data and are considered missing coverage. All images were pre-processed, mosaicked, and classified for snow cover using the multitemporal method outlined below.

The Landsat snow cover CDR demonstrated is a prototype time-series of June 1 SCA for the central Idaho and southwestern Montana mountains (Fig. 1). This June 1 CDR captures SCA variability during peak snowmelt for 1975-2011 (Figs. 2 and 3). Much of the SCA on or near June 1 for this region is confined to mid-high elevations low elevation zones have already melted out. The central Idaho and southwestern Montana mountains are situated within a continental semi-arid climate zone (Mitchell, 1976) with both local and regional hydrological significance. These snow-fed rivers and tributaries form the headwaters of the Columbia and Missouri River basins and support potable water uses, hydropower generation, fishery migration, agricultural irrigation, and recreation.

\subsection{Landsat snow cover CDR design}

Seasonal mountain snowpack across the Idaho-Montana region begins to accumulate in mid-October and reaches maximum SWE around early-mid April (Cayan, 1996). During the winter season (December-March), SCA in mountainous terrain more or less remains near maximum coverage at high elevations with lower elevations exhibiting daily-weekly variability due to short-term meteorological conditions. Once spring arrives, snow cover (snowpack) begins to successively melt with increasing solar irradiance, decreasing albedo, and warming springtime temperatures. Thus, variability in mountain SCA during snow accumulation and snowmelt periods has been, is, and will continue to be retrieved by each Landsat overpass.

Landsat snow cover CDR development is limited by the 16-18 day repeat schedule, which roughly corresponds to a bi-monthly interval. This temporal structure enables the potential to fully use all available Landsat images through compositing, especially in areas where image overlap allows 8-9 day coverage. Landsat snow cover CDRs are based on SNOTEL SWE bi-monthly sampling intervals centered on days 1 and 15 of each calendar month (Serreze et al., 1999), where Landsat images on days 8-22 are assigned to the mid-month interval, and days 23-7 mark the end-beginning month interval (Fig. 2). These discrete bi-monthly intervals allow for SCA to be mapped at seasonal, interannual, and decadal timescales across a defined spatial domain. This spatial domain involves a latitude-longitude grid that covers an explicit geographic area. This Landsat CDR grid design provides a workable geographic scale to manage data volume and overlapping images, preserve spectral properties, and facilitate statistical integration with gridded ground-based instrumental climate records.

\subsection{Image registration}

Geo-referencing images to a target coordinate system requires either ground control points or ancillary spatial data such as a digital elevation model (DEM) to accurately assign pixels to an exact latitudelongitude position (Seidel et al., 1983). Most available Landsat images from the EROS Data Center have already been processed to a standard-level of geometric and terrain accuracy (http://landsat. usgs.gov/Landsat_Processing_Details.php). Geometric errors may 


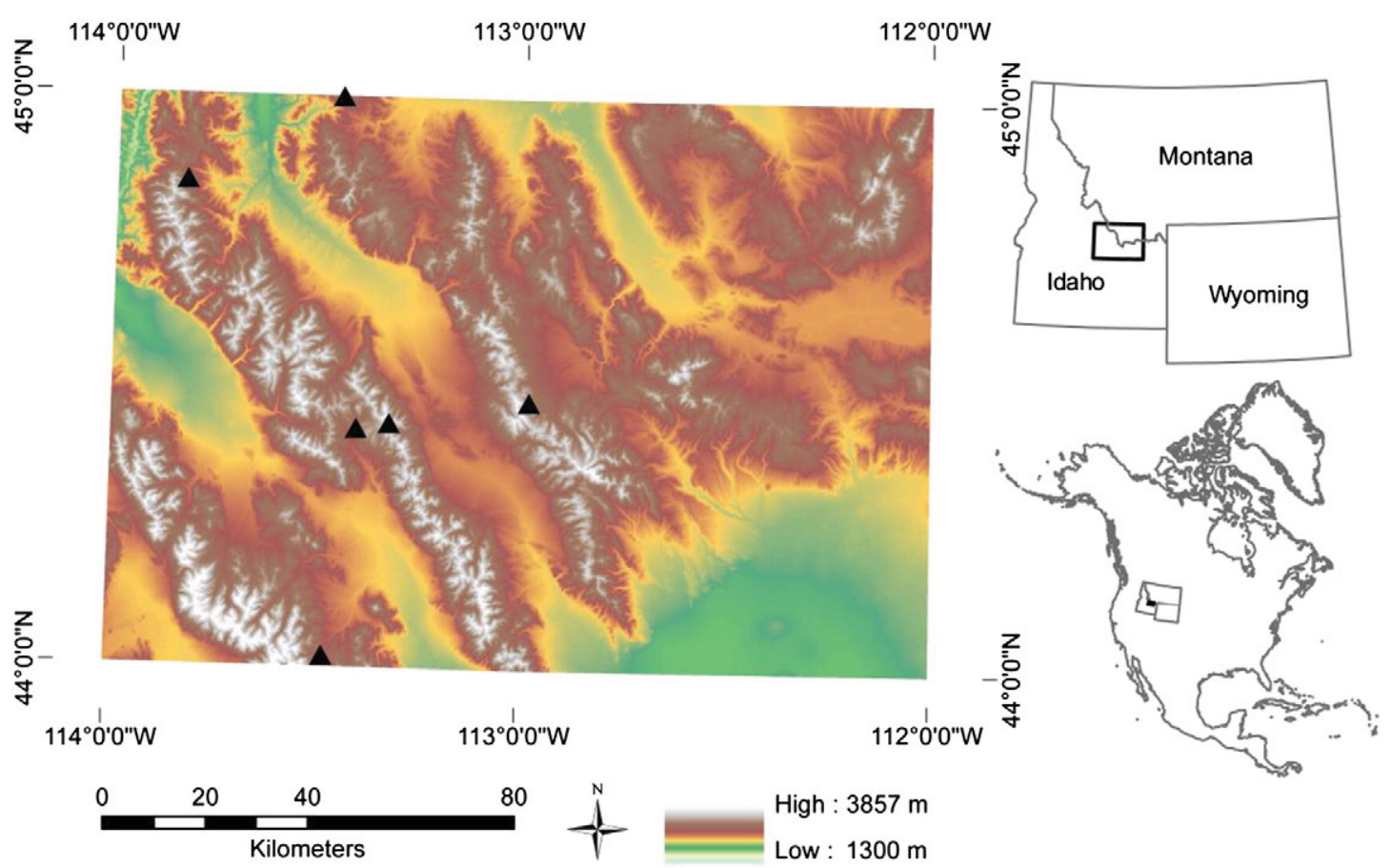

Fig. 1. Central Idaho-southwestern Montana snow cover CDR region. The black triangles show SNOTEL SWE measurement sites used for bi-monthly snow cover CDR design.

exist with older MSS images. This requires careful treatment on an image basis when assembling multitemporal sequences.

For this multitemporal method, unregistered images are georeferenced to a geometrically accurate image (i.e., preferably the same sensor with minimal cloud coverage) using an automatic tie-point algorithm. Automatic tie-points are selected by correlating the unregistered image with a geo-referenced image using a distributional grid of stratified points with maximum correlation. An affine transformation is then applied to generate a Root Mean Squared Error (RSME) statistic. A RSME threshold of less than 0.5 (i.e., half the pixel resolution) is the geometric accuracy standard for Landsat snow cover CDRs.

\subsection{Radiometric calibration}

Radiometric normalization across multiple sensors and different dates of imagery is required to preserve spectral-radiometric properties and temporal consistency between multitemporal image sequences (Chander et al., 2009; Chavez, 1996; Song et al., 2001). For example, sensor radiometric differences exist between Landsat MSS, $\mathrm{TM}$, and ETM + platforms because spectral bandwidths have been placed at different wavelengths along the electromagnetic spectrum. This influences retrieval of pixel-level spectral radiance across a continuous spectrum. Furthermore, each image was acquired on different days where atmospheric conditions and illumination angles in

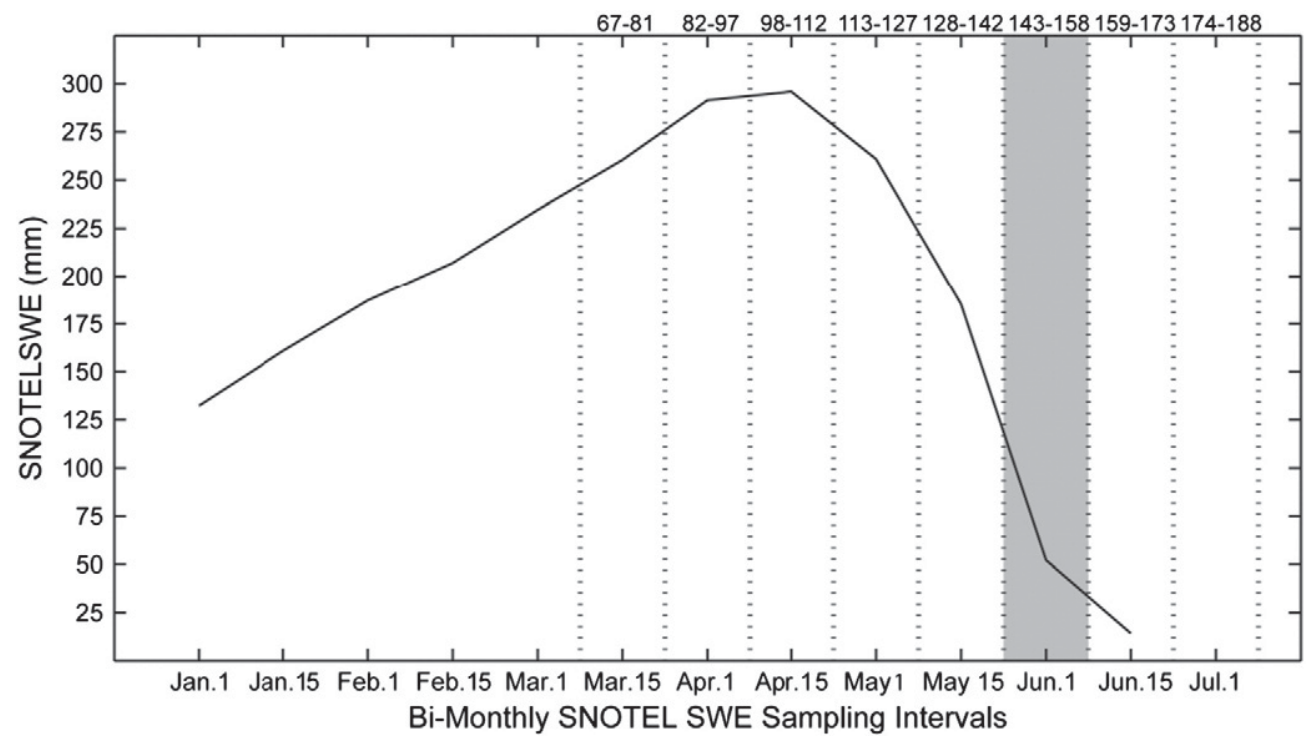

Fig. 2. Bi-monthly Landsat snow cover CDR design. All available Landsat images from the entire image archive are assigned into discrete bi-monthly Julian sampling intervals. The thick black line represents a snowpack accumulation-melt curve based on observed mean bi-monthly SWE measurements for 1976-2010. Mean SWE estimates were derived from a regionalization of six SNOTEL sites across the study region (http://www.wcc.nrcs.usda.gov/snow). The gray shading indicates the June 1 Landsat snow cover CDR bi-monthly interval. 


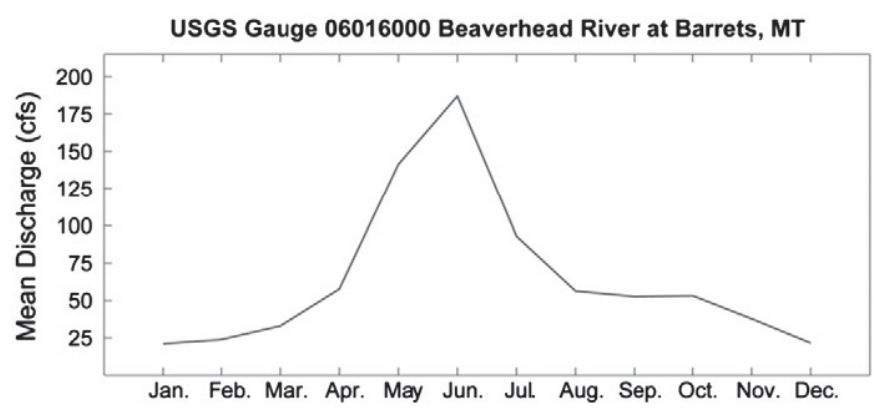

USGS Gauge 13118700 Little Lost River BL Wet Creek NR Howe, ID

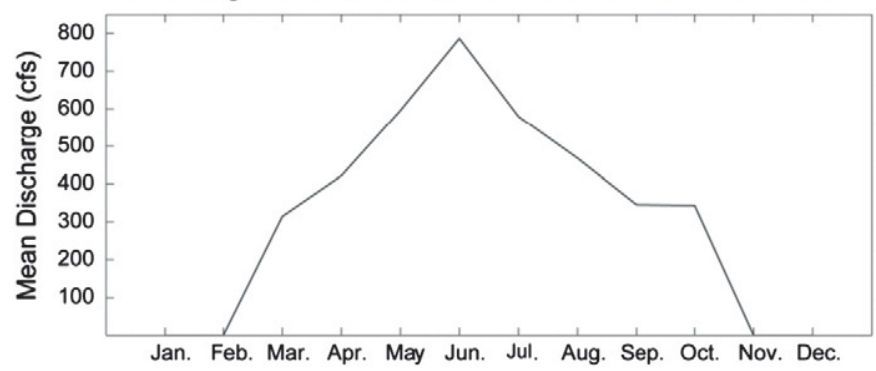

Fig. 3. Gauged mean monthly discharge, cubic feet per second (cfs) for Little Lost and Beaverhead Rivers in central Idaho and southwestern Montana. Historical mean monthly discharge estimates for Little Lost (1958-2011) and Beaverhead (19082011) gauges were summarized for the period of record. Beaverhead discharge estimates for Nov. -Feb. were not available for the full period of record. Note: discharge estimates are provisional and subject to revision by the USGS.

mountainous terrain were variable between images (Meyer et al., 1993). Given these between sensor and multi-date differences, each image must be standardized by calibrating to an absolute radiometric scale.

Landsat imagery downloads from the EROS Data Center are delivered in a geotiff format that contains raw unprocessed digital numbers (DN values). Radiometric calibration first requires that DN values for each spectral band be converted to an at-sensor radiance value using Landsat sensor-specific calibration coefficients (Chander \& Markham, 2003). Calibration coefficients ensure that at-sensor radiance measurements acquired during the sensor's mission incorporate corrections for measurement changes, mechanical malfunctions, and instrument deterioration (Chander et al., 2007, 2009). Landsat images used for snow cover CDR development have been calibrated using the published calibration parameter files (http://landsat.usgs.gov/science_calibration.php).

The next step in radiometric calibration involves converting the at-sensor radiance to a planetary reflectance value. This at-sensor reflectance conversion can either be implemented for the top-of-the-atmosphere (TOA) or the surface (Chander et al., 2009; Vermote \& Kotchenova, 2008). Several atmospheric correction methods have been developed, and often include either a partial or full correction that relies on ancillary data inputs (Chander et al., 2009; Chavez, 1996; Coppin \& Bauer, 1994; Song et al., 2001; Vermote \& Kotchenova, 2008; Vermote et al., 1997). These model inputs include spectral band solar irradiance, earth-sun distance, sun elevation, optical thickness, and atmospheric aerosols, but even so, it remains unclear whether a full atmospheric correction actually produces superior results (Song et al., 2001). For Landsat snow cover CDRs, a TOA conversion following the methods in Chander et al. (2009) was applied using a cosine correction to account for diffuse irradiance. This TOA conversion was decidedly appropriate at a minimum for preserving radiometric consistency across multiple Landsat sensors.

\subsection{Cloud masking}

Cloud cover contamination remains a significant challenge for optical remote sensing in planetary regions where climatological patterns produce transient, frequent, and persistent cloud cover. Since the
Landsat image record contains partially cloudy images, a robust cloud-masking algorithm to remove cloudy pixels is required. Several cloud-masking approaches have been developed for specific sensor-platforms (Ackerman et al., 1998; Hagolle et al., 2010; Huang et al., 2010; Irish et al., 2006) that use multispectral band criteria to examine reflectance change and the thermal band to further separate cloudy pixels from non-cloudy pixels. Landsat specific algorithms include the automated cloud cover assessment (ACCA) algorithm developed by Irish et al. (2006) to estimate cloud cover content on Landsat ETM + images. More recently, Huang et al. (2010) developed a Landsat cloud algorithm that uses a DEM, the thermal band, and cloud-free confident forest pixels to identify cloudy pixels. Most studies agree that including the thermal band improves algorithm performance (Hagolle et al., 2010; Huang et al., 2010; Irish et al., 2006).

Although the ACCA is computationally complex and process intensively by design, this algorithm is able to separate pixels containing snow from pixels containing clouds, and distinguish warm clouds from cold clouds using spectral signatures and thermal band cloud population statistics. The ACCA takes advantage of TM and ETM + bands 26 by engaging a four-step process that first develops spectral and thermal band cloud signatures, performs thermal band cloud separation, assigns and aggregates cloudy pixels, and fills cloud holes (Irish et al., 2006). Lack of middle infrared and thermal spectral bands on MSS limits automatic detection of clouds, shadows, and discrimination between snow and clouds. Clouds and shadows were subjectively removed by visually identifying neighborhoods of dark pixels (i.e., shadows) that were adjacent to brightly illuminated pixels (i.e., clouds).

\subsection{Shadow masking}

Cloud shadows are an inevitable outcome of cloud cover contamination. The spectral characteristics of cloud-shadow pixels are largely absorptive with dark low reflectance responses across visible, near and middle infrared wavelengths. The aerial extent of cloud-shadow contamination is contingent on time of year, time of acquisition, latitudinal position, topographic relief, cloud area, cloud height, and solar illumination. Because cloud shadows share a similar spectral response with water and heavily shaded mountainous slopes, simple spectral reflectance thresholding is not adequate for shadow detection. Hutchison et al. (2009) and Huang et al. (2010) have developed a cloud-shadow detection method that includes cloud pixel location, cloud pixel height, and solar geometry inputs to project shadow pixel location. Once shadow pixel locations have been approximated, a moving window is engaged to guide the search for shadow pixels exhibiting distinct spectral reflectances (Hutchison et al., 2009).

Applying the solar geometry cloud-shadow detection method first requires a cloud mask. Next, a cloud height estimate is computed for each cloudy pixel using both daily surface air temperature (i.e., image acquisition date) and Landsat band 6 pixel temperature. Daily mean surface air temperature observations used for cloud height estimation originate from the NCEP 10-meter reanalysis network (Kalnay et al., 1996; Masek et al., 2006). For cloudy pixels, normalized temperature anomalies are calculated by subtracting band 6 temperatures from the surface air temperature. Using the normal lapse rate conversion of $6.4{ }^{\circ} \mathrm{C}$ decrease for every 1000 -meter vertical increase, cloud heights for each pixel can be approximated (Huang et al., 2010). Below the standard pressure level of $700 \mathrm{hPa}$, temperature change does not always obey the normal lapse rate (Minder et al., 2010). In these instances, approximated cloud heights may be substantially over or underestimated. Also, actual shadow locations are cast from cloud bottoms rather than cloud tops; therefore, thermal band optical depth may contribute additional uncertainty to cloud height estimates. To reduce uncertainty, a range of cloud-shadow projections for each pixel is generated using a scale factor (i.e., cloud height multiplied by 1.5 or 2 for example) in the denominator of the cloud-shadow projection equation (Hutchison et al., 2009; Masek et 
al., 2006). The final step involves using a moving window with a local neighborhood operation to find pixels that show a shadow spectral response. A 20 by 20 pixel window (Hutchison et al., 2009) is used to search for projected shadow pixels with a spectral reflectance of $<0.10$ for the near infrared (band 4 ) and $<0.10$ for the middle infrared (band 5) wavelengths. If a pixel satisfies this threshold criterion, it is flagged as a shadow (Huang et al., 2010).

\subsection{Topographic normalization}

Land surface radiance represents a combined response to direct and diffuse solar irradiance that reflects the sun's illumination angle and local topographic angle during time of overpass (Dozier \& Frew, 1990; Lu et al., 2008; Meyer et al., 1993; Smith et al., 1980; Teillet et al., 1982). This spectral response is wavelength and land cover dependent (Meyer et al., 1993), and in mountainous terrain, these effects are especially pronounced because of steep slopes and directly opposing aspects. As a result, images with mountainous terrain need to be normalized for both the sun's zenith angle and local illumination angle. Teillet et al. (1982) and others suggest that applying this correction is particularly important for multitemporal image analysis, and for improving classification accuracy.

Several quantitative methods for reducing topographic effects have been proposed that require empirical or semi-empirical correction parameters (Meyer et al., 1993). A key parameter of any correction method is whether Lambertian flat surface scattering is assumed. Smith et al. (1980) found that for Landsat MSS data, a Lambertian assumption was generally correct only for slopes below $25^{\circ}$ and sun zenith angles less than $45^{\circ}$. As an alternative, Minnaert's correction is generally a preferred method, and requires a derivation of an image specific $k$ value that measures the degree to which a surface is Lambertian. Landsat CDRs include an image-based Minnaert correction to reduce topographic effects. Using a 10-meter USGS DEM and sun elevation and azimuth parameters contained within the image metadata, illumination layers are generated following the equations found in Meyer et al. (1993). The local illumination DEM layer is then resampled to 30-meter pixels using a nearest neighbor calculation. A stratified random sample from slopes greater than $20^{\circ}$ are then collected from the local illumination layer and the Landsat illumination image to derive $k$. Both populations are log transformed, and using linear regression, the slope of the regression line $(k$ value) is computed for TM and ETM + spectral bands 1-5 and 7, and MSS spectral bands 4-7. Finally, Minnaert's correction is applied back to each spectral band using wavelength specific $k$ values.

\subsection{Image mosaicking}

When mapping regions where multiple Landsat images cover a target spatial domain, mosaicking is required to obtain a composite image. The main objectives for mosaicking are to maximize cloud-free coverage, piece together images from multiple sensors having different image properties, and ensure that original spectral-radiometric properties have not been compromised. Landsat CDRs hierarchically select images having the lowest cloud cover content to serve as the target image. Image mosaicking is then executed using a simple computational overlap function.

Landsat's 16-18 day image acquisition frequency does limit snow cover mapping. In some instances, Landsat's coverage may not be able to resolve the difference between resident snow cover and transient snowfall (Li et al., 2008). This would result in a tendency to inflate SCA, but even so, individual SCA anomaly years could be identified using statistical tests and ancillary information from SNOTEL SWE, daily MODIS SCA maps, and/or preceding bi-monthly Landsat snow cover CDRs. Mosaicking Landsat images from different acquisition dates, sometimes even five to seven days, does present a caveat for snow cover mapping.

\subsection{Snow cover classification}

Snow is highly reflective at visible wavelengths, and is clearly distinguishable from other land surface features (Hall \& Martinec, 1985; Seidel \& Martinec, 2004). Clouds are also highly reflective, but diverge with snow at middle infrared wavelengths. While middle infrared cloud reflectances remain high, reflectances for snow are absorptive (Dozier, 1989; Hall et al., 1995). Spectral bands at visible and middle infrared wavelengths allow for spectral discrimination between snow and clouds (Dozier \& Painter, 2004; Hall et al., 1995). Classifying snow cover in multispectral imagery is accomplished using either a binary (Seidel \& Martinec, 2004) or fractional method (Rosenthal \& Dozier, 1996; Salomonson \& Appel, 2004). These two approaches stem from the normalized difference snow index (NDSI), a spectral band ratio, or subpixel unmixing, a simultaneous linear equation that separates vegetation, soils, and lithology endmembers from snow. Both methods have been shown to yield acceptable snow cover classification accuracy (Hall \& Riggs, 2007; Hall et al., 1995, 1998, 2000, 2001, 2002a; Rittger et al., 2012; Salomonson \& Appel, 2004). The NDSI uses TM and ETM + bands 2 and 5, and MODIS bands 4 and 6 (Hall \& Riggs, 2011). Pixels with snow cover greater than 50\% have been found to have a NDSI value greater than 0.4 (Hall \& Riggs, 2011; Hall et al., 1995). Klein et al. (1998) find that snow beneath dense forests can degrade the NDSI response. They suggest including a normalized difference vegetation index (NDVI) threshold in conjunction with NDSI to improve snow cover detection because the spectral response of vegetation with snow has low NDVI values.

\subsubsection{TM and ETM +}

Landsat snow cover CDRs from TM and ETM + use NDSI to retrieve and binary classify pixel level snow presence (absence) greater (less) than 50\% snow cover. This threshold-based snow classification scheme for Landsat mimics the MODIS method (Riggs et al., 2006). Landsat pixels are classified as snow if NDSI is greater than 0.4 , band 2 is greater than 0.11 , and band 4 is greater than 0.10 . The band 2 threshold aids in the discrimination between snow and water, and the band 4 threshold prevents dark targets as being erroneously identified as snow (Riggs et al., 2006). At this time, the NDVI threshold (Klein et al., 1998) has been excluded because of Landsat's fine spatial resolution, and uncertainty whether this response inflates the snow signal during the spring melt season. Excluding this criterion from the Landsat NDSI classification scheme possibly reduces SCA in dense forest and around the snow-covered to snow-free transition zone.

\subsubsection{MSS}

MSS snow-cloud separation is not possible using an automated approach. As stated earlier, cloud cover was visually identified using shadow detection as a guiding criterion, and then cloud and shadow pixels were manually removed. Because clouds and shadows have been removed during MSS image processing, highly reflective pixels indicate snow cover presence. Using an ISO data-clustering algorithm on MSS bands, 30 individual classes are initially identified using spectral band means and standard deviations. Each class is then interpreted to be snow or snow-free. Only cluster classes showing a clear homogenous snow cover response are selected for classification. Pixels having a mixed snow cover signal are difficult to identify because of the mixed spectral responses from snow-free surfaces (Dozier \& Painter, 2004; Rosenthal \& Dozier, 1996).

\subsection{Landsat SCA estimation}

Landsat snow cover CDRs are constructed on bi-monthly timescales to estimate SCA from multispectral measurements over a spatially explicit domain. Every useable Landsat image from the archive is pre-processed, classified for snow cover, and input into a Landsat image chronology. An inevitable component of CDR construction is 
that visible Landsat image coverage will vary over time. For a given spatial domain, total land surface area $\left(\mathrm{m}^{2}\right)$ is calculated using a $10-\mathrm{m}$ USGS DEM. This area calculation is the total amount of land surface area that snow can cover at any time including inland water bodies. This rationale forms the basis for a normalized SCA estimate that is independent from image coverage. Landsat SCA percent coverage for each annual bi-monthly interval is estimated using the following equation:

Normalized SCA $=\left[\begin{array}{c}\text { visible } \mathrm{SCA}\left(\mathrm{m}^{2}\right) /\left(\text { land surface area }\left(\mathrm{m}^{2}\right)\right. \\ -\left(\text { missing visible coverage }\left(\mathrm{m}^{2}\right)\right. \\ \left.\left.+ \text { cloud }- \text { shadow contamination }\left(\mathrm{m}^{2}\right)\right)\right)\end{array}\right]$

This ratio assumes no change in land surface area, only a change in visible coverage and SCA. An estimate of visible coverage also accompanies Landsat snow cover CDRs. Normalized SCA estimates can be derived from four possible image combinations: cloud-free, partially cloudy, partially cloudy with SLC-off, and partially cloudy with missing coverage (Fig. 4).

\subsection{Landsat CDR homogeneity}

Ground-based, upper air, and satellite CDR homogeneity has and remains a long-standing data development, production, and distribution objective (Peterson et al., 1998). This quality control process is particularly important for historical records, and ensures that climate data users can access, analyze, and interpret specific datasets without concern that 'non-climatic' factors such as technological change, instrumentation location change, or measurement protocol have influenced the observations in time (Peterson et al., 1998). For historical satellite retrievals, these 'non-climatic' factors can largely be addressed during image pre-processing, but for Landsat snow cover CDRs, additional quality assurance steps are required to account for missing image coverage and cloud-shadow contamination when estimating normalized SCA.

If systematic biases are embedded within Landsat snow cover CDRs, they will originate from either missing image coverage, clouds, shadows, or forest canopy effects (Kane et al., 2008). A primary concern for Landsat snow cover mapping, especially historical imagery, is that the accumulated and combined effects of image acquisition frequency, visible coverage, and cloud-shadow contamination will introduce uncontrollable 'non-climatic factors' into the SCA estimation. Even though snow cover distribution and scaling across mountainous terrain have been shown to be possible (Seidel \& Martinec, 2004), identifying spatially where potential error could emerge is necessary for assessing Landsat CDR quality and homogeneity in time.

Pixel level relative frequency maps of missing image coverage were assembled using no coverage, cloud, and shadow masks derived during image processing. MSS and TM/ETM + frequency maps were assembled separately because of differing pixel resolution and methods for constructing cloud and shadow masks. Relative frequency maps for MSS and TM/ETM + visible and non-visible (i.e., combined
A
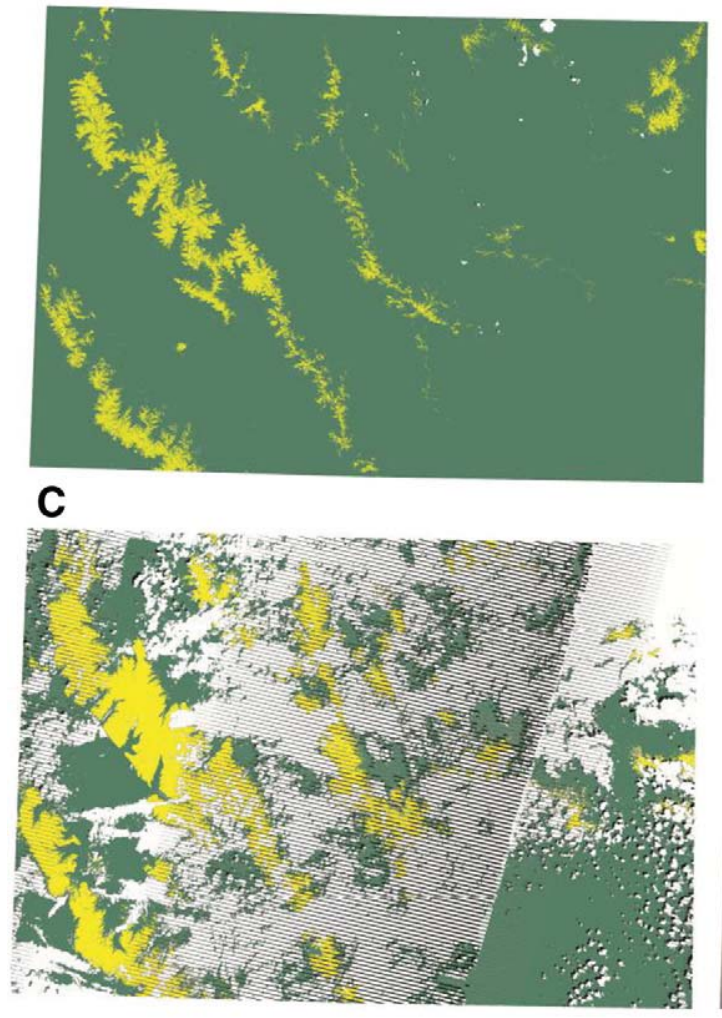

B

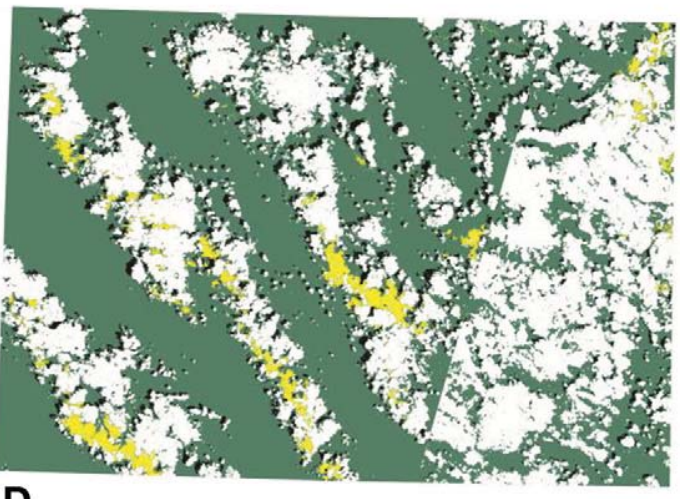

D

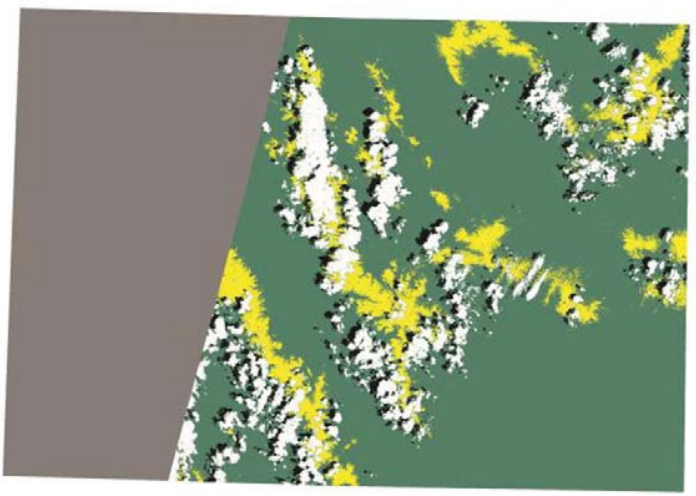

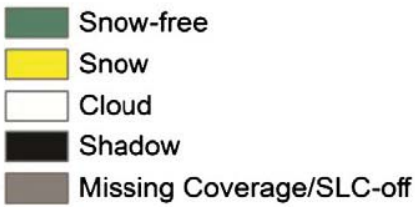

Fig. 4. Possible Landsat image combinations for normalized SCA estimation: a) cloud-free SCA map; b) partially cloudy SCA map; c) partially cloudy SCA map with SLC-off; and d) partially cloudy SCA map with missing coverage. 
missing coverage, clouds, and shadows) pixels were tallied across the Landsat CDR.

\subsection{Landsat $C D R$ statistical quality}

Time-series data usually originate from equally spaced continuous observations in time (i.e., Landsat images), and are derived based on discretely measured values (i.e., SCA) at specific time periods (Chatfield, 2004). Time-series theory requires that a non-stationary stochastic process with periodic and/or seasonal variations are transformed into a stationary process, in this case Landsat SCA, where there is no systematic change in the mean or variance over time (Chatfield, 2004). Landsat snow cover CDRs are designed to capture bi-monthly SCA with the motivation to statistically merge SCA with other related climatic time-series such as SWE, temperature, and precipitation. Before doing so, it is important to evaluate whether the proposed normalized SCA equation produces a scale independent, normal SCA probability distribution that is stationary in time.
To quantify that SCA is scale independent in horizontal and vertical domains, two separate snow cover CDRs have been derived using elevation as a standardized control. The first June 1 SCA CDR has been constructed for the full spatial domain, and the second has been constructed for the alpine domain above $2500 \mathrm{~m}$. Lilliefor's test for normality is used to determine whether SCA has a normal or non-normal statistical distribution with an unspecified mean and variance (Conover, 1980). Student's t-test for correlated samples, and simple correlation is used to test whether SCA mean and variance is statistically different, and shares statistically significant covariance if constrained by scale parameters.

\section{Results}

June 1 SCA estimates were produced for 30 of the 39 possible years. The June 1 SCA CDR for central Idaho and southwestern Montana spans 1975-2011 with missing years in 1973, 1974, 1978-1982, 1987, and 1988 because of either missing coverage or cloud-shadow
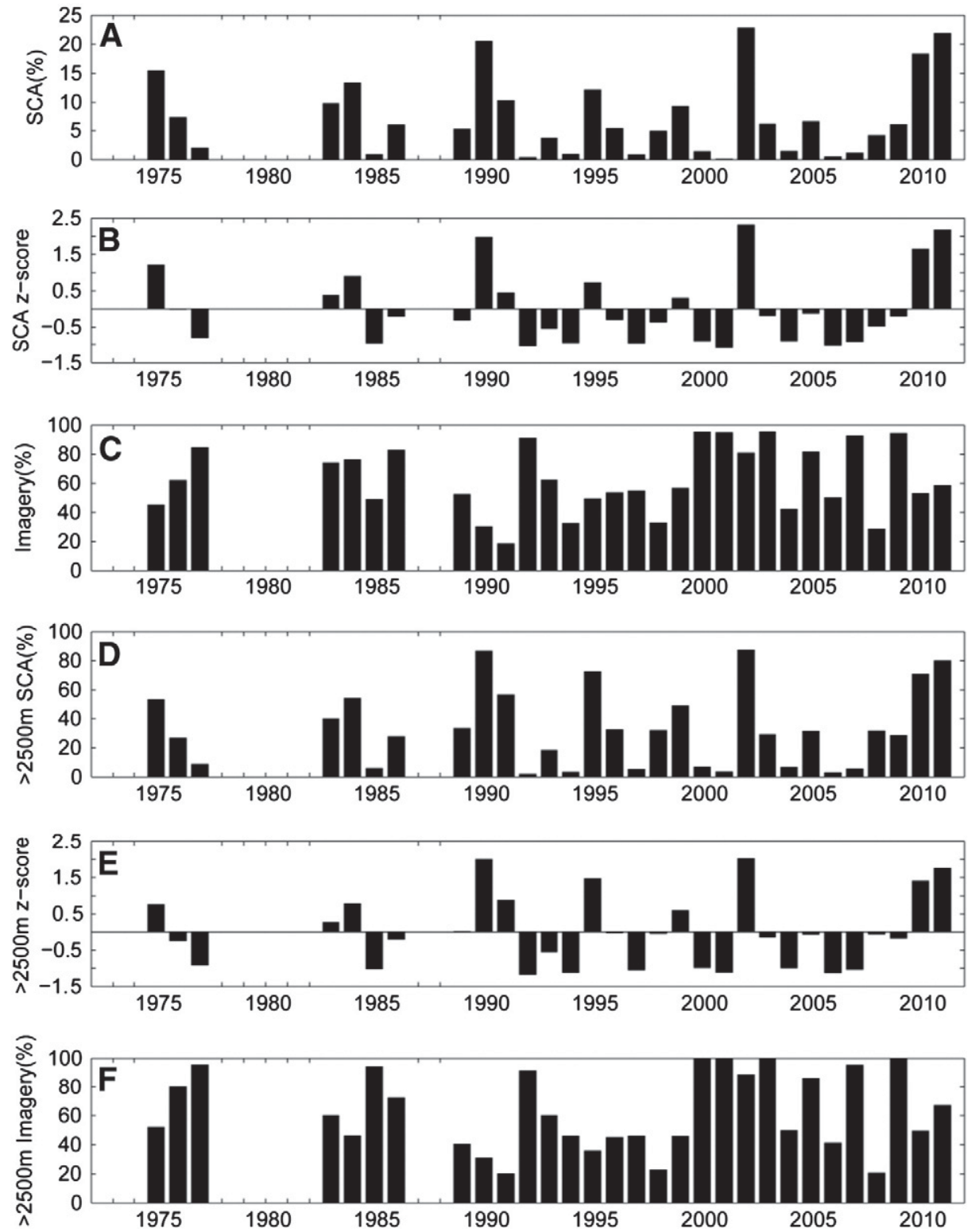

Fig. 5. Landsat June 1 snow cover CDR: a) June 1 SCA estimates for the full spatial domain; b) full spatial domain standard normal SCA estimates using the 30-year SCA mean and standard deviation; c) percent visible image coverage for each full domain SCA estimate; d) June 1 SCA estimates for the alpine domain above 2500 m; e) alpine domain standard normal SCA estimates using the 30-year SCA mean and standard deviation; and f) percentage of visible image coverage for each alpine domain SCA estimate. Years 1973, 1974, 1978-1982, 1987, and 1988 are missing SCA estimates and are marked with line ticks. 
contamination (Fig. 5). Pixel level relative frequency maps show that if SCA estimation is biased, it is more influenced by missing image coverage than cloud-shadow contamination (Fig. 6). Each TM/ETM+ (Fig. 6a) and MSS (Fig. 6b) frequency map reveals areas across the full spatial domain having missing coverage that closely resembles adjacent Landsat path-row swath coverage. In the MSS map, scanline striping and manually edited cloud-shadow cover polygons are evident.

Lilliefor's test for normality confirmed that the June 1 SCA estimates are non-normal even with a sample size of 30 years (Table 2). It is important to note that the June 1 SCA estimates for 1990 and 2002 have been identified as statistical outliers, and may be influenced by transient snowfall at higher elevations during the melt season. Student's t-test for correlated samples between separately derived full and alpine domain (i.e., above $2500 \mathrm{~m}$ ) June 1 SCA CDRs indicates a statistical difference between the mean and variance (Table 3). The correlation coefficient between June 1 SCA CDRs is 0.97 ( $\mathrm{p}<0.001$, two-tailed).

\section{Discussion}

The Landsat mission and its moderate spatial resolution, unequaled image record length, and acquisition schedule can supplement operational SCA mapping on bi-monthly to decadal timescales. Bi-monthly snow cover CDR design and development is based on using multispectral images from multiple sensors to retrieve SCA during bi-monthly SNOTEL SWE measurement intervals collected across the western US. However, this multitemporal snow cover mapping method does have inherent limitations that need to be fully acknowledged from the outset. Primary limiting factors include data gaps in historical coverage, image acquisition frequency, and the potential for transient snowfall during snow accumulation and snowmelt seasons. Secondary limitations originate from differences between sensor-specific spectral and spatial resolutions, as well as frequent

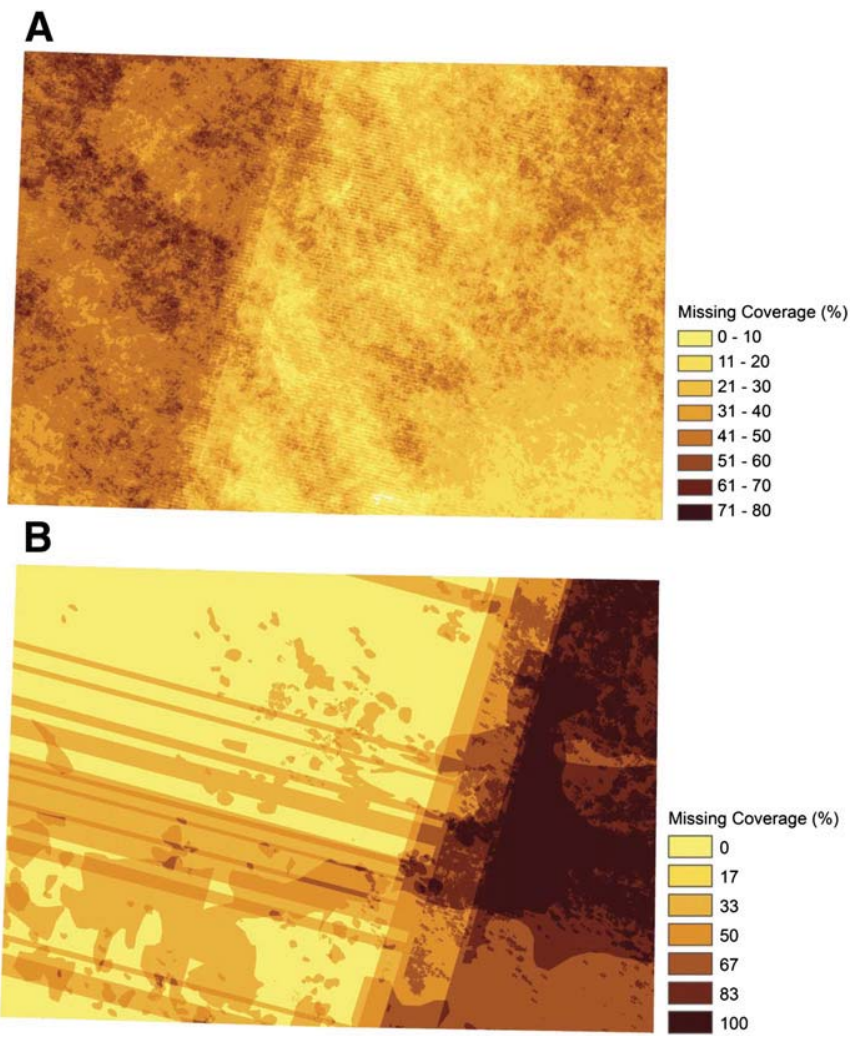

Fig. 6. Pixel level relative frequency maps of missing image coverage including cloud and shadow contamination: a) TM/ETM + missing coverage for 24 years between 1985 and 2011; and b) MSS missing coverage for six years between 1973 and 1992.
Table 2

Lilliefor's normality test for June 1 SCA estimates.

\begin{tabular}{lllllll}
\hline $\begin{array}{l}\text { Landsat } \\
\text { CDR }\end{array}$ & $\begin{array}{l}\text { Record } \\
\text { length* }\end{array}$ & $\begin{array}{l}\text { Samples } \\
(\mathrm{n})\end{array}$ & Lilliefor's & Critical-value & p-value & Decision \\
\hline $\begin{array}{c}\text { June 1 SCA- } \\
\text { Full }\end{array}$ & $1975-2011$ & 30 & 0.176 & 0.158 & 0.017 & Reject \\
$\begin{array}{c}\text { Domain } \\
\begin{array}{c}\text { June 1 SCA- } \\
\text { Alpine }\end{array}\end{array}$ & $1975-2011$ & 30 & 0.160 & 0.158 & 0.044 & Reject \\
\hline
\end{tabular}

Decision: The null hypothesis is that SCA estimates come from a normal distribution with an unspecified mean and variance.

Record length*: SCA estimates are not available for all years because of missing imagery or cloud-shadow contamination.

cloud cover contamination over mountainous terrain. For MSS images, manual removal of clouds and shadows presents a considerable challenge for operational snow cover mapping at the global scale, although regional mapping efforts may be more feasible. While these limitations do present considerable roadblocks when processing Landsat images for SCA estimation, taking advantage of additional image data from MODIS for example, and/or SNOTEL SWE, may offer viable options for filling in temporal data gaps, identifying transient snow cover anomalies, and increasing cloud-free coverage.

Radiometric calibration across the Landsat missions is a critical requirement for CDR development. Feng et al. (2012) have developed the Landsat-MODIS Consistency Checking System, and present a framework for operational Landsat surface reflectance production. In terms of this multitemporal method, a full atmospheric correction to surface reflectance is not attempted at this time because of operational and computational constraints locally. Instead, a TOA correction is applied that currently excludes optical thickness, atmospheric aerosols, and water vapor corrections common to MODIS products (Vermote \& Kotchenova, 2008). Moving beyond current constraints into operational Landsat CDR production would likely yield a 'more correct image product' as the benchmark, but regardless, re-processing of image archives can be expected in the future given advancements in algorithm development and computing (Dozier \& Frew, 2009). At this time, the above TOA method at a minimum provides temporal and radiometric consistency between Landsat sensors and image inputs into Landsat snow cover CDRs. The prototype Landsat snow cover CDR presented should be accepted as an initial product, but not final in form.

Landsat normalized SCA estimation is based on the assumption that land surface area over a geographically explicit spatial domain constrains and normalizes SCA variance over discrete bi-monthly intervals. The normalized SCA equation proposed also assumes that reliable SCA estimates can be derived independently from the variation in visible image coverage. Cloud-free coverage is not a realistic expectation for Landsat's image archive, image acquisition frequency, or imagery over mountainous terrain. If Landsat's historical image archive is to be used comprehensively in innovative ways, accepting that target land surface variables, in this case mountain SCA, can be derived from partially cloudy images is essential. Currently, Landsat snow cover CDRs exclude SCA underneath clouds although spatial modeling methods for snow cover extrapolation are available using

Table 3

Student's two-sample t-test between June 1 SCA estimates.

\begin{tabular}{llll}
\hline & Full domain SCA & Alpine domain SCA & Total \\
\hline $\mathrm{n}$ & 30 & 30 & 60 \\
$\sum \mathrm{x}$ & 2.182 & 9.902 & 12.084 \\
$\sum \mathrm{x}^{2}$ & 0.293 & 5.357 & 5.650 \\
$\mathrm{SS}$ & 0.134 & 2.088 & 3.216 \\
Mean & 0.072 & 0.330 & 0.201 \\
Full SCA mean-Alpine SCA mean & $\mathrm{t}$ & $\mathrm{df}$ \\
-0.257 & $-6.93^{*}$ & 29 & \\
\hline
\end{tabular}

Two-tailed significance: $\mathrm{p}<0.001^{*}$. 
ancillary data, and have shown acceptable performance for images with up to $30 \%$ cloud cover obstruction (Seidel \& Martinec, 2004). Once Landsat snow cover CDRs have been developed for multiple bi-monthly intervals, it may be possible to explore whether implementation of a SCA extrapolation model is operationally feasible, and substantially improves SCA estimation.

The pixel level 'salt and pepper' effect on each frequency map suggests that over time, cloud-shadow contamination is spatially random with greater likelihood of non-randomness directly over mountain peaks. Systematic missing image coverage is largely an artifact of missing Landsat path-row images on historical timescales. More broadly conceived, when missing image coverage is concentrated over specific mountain ranges, then SCA estimation may have greater uncertainty; however, if missing image coverage is concentrated over lower elevation snow-free land, then SCA estimation may by less influenced by missing image coverage. At this time, Landsat snow cover CDR design and development appears to have few systematic biases other than data driven constraints such as missing imagery. Landsat CDR homogeneity and quality control should remain a high research priority because achieving temporal consistency and spatial accuracy is critical for climate-based study in mountainous terrain.

Landsat snow cover CDRs form the basis for monitoring spatiotemporal variability in mountain SCA, and identifying primary climatic controls on mountain snowpack extent. The SNOTEL network is able to resolve SWE variability at discrete locations, which could be helpful for distinguishing between temporal variability in SWE and SCA. One primary statistical challenge that accompanies Landsat snow cover CDR evaluation is obtaining enough SCA estimates over time to satisfy the assumptions of normality and parametric statistical modeling and inference. It is well known that instrumental ground-based precipitation observations have non-normal distributions largely attributed to spatial variability in precipitation (Jones \& Hulme, 1996). Landsat SCA estimates are likely to also be non-normal similar to precipitation. This may limit identification of a known SCA mean and standard deviation with the current record. Achieving normality for Landsat CDRs will only come from first, adding more temporal SCA estimates to the probability distribution over longer-timescales, and second, correcting for transient snowfall in SCA estimation.

A comparison between full and alpine domain SCA CDRs suggests that normalized SCA estimates are stationary, but are statistically non-normal. SCA CDRs do show statistically significant covariance in time even though scale parameterization influences the mean and variance. Increasing the spatial extent of the June 1 snow cover CDR to include adjacent regions would likely increase the ability to estimate SCA more continuously during the 1970s and 1980s. The development of longer Landsat snow cover CDRs on past and future timescales will offer greater certainty when determining temporally significant SCA trends.

Multitemporal snow cover mapping in mountainous terrain is now possible dating back to 1973 using Landsat. Snow cover CDR development provides a historical starting point for monitoring fine scale variability in mountain SCA at bi-monthly timescales and beyond. Missing historical Landsat coverage is inherent to the image record, and should be considered a data-driven factor, not a data source limitation. This multitemporal method is operationally executable and grounded in well-validated algorithm selection and performance. Refinements to this multitemporal method should be expected in the future given algorithm advancement, greater computing capacity, additional imagery acquired during the Landsat Data Continuity Mission (LDCM), and the potential for multi-sensor integration between MODIS and Visible Infrared Imaging Radiometer Suite (VIIRS).

Using Landsat to monitor historical changes and trends in mountain snowpack extent through snow cover CDRs is innovative, warranted, and can support climate variability and change study, hydroclimatological modeling and prediction, and freshwater resource projections under climatic warming. Future work will merge
Landsat snow cover CDRs with SNOTEL SWE and surface temperature and precipitation observations to not only identify the temporal climatic controls on mountain SCA, but also enable long-term versus short-term trend detection over the 20th and 21st centuries. This multitemporal method is widely applicable to all mountainous regions where snow cover accumulates and melts annually, and Landsat imagery is available. The proposed method is intended to guide Landsat snow cover CDR development across the western US.

\section{Acknowledgements}

A NASA Earth and Space Science Fellowship grant number NNX10A073H, an Association of American Geographers Dissertation Research Grant, and an Association of American Geographers Mountain Geography Specialty Group Research Grant funded this research. We would like to thank George Riggs, James Foster, and Mike Mommsen for constructive feedback during the development of this research and manuscript preparation. Additional thanks are extended to Kurt Kipfmueller and Scott St. George for assistance with MATLAB image processing code development. We are also grateful for anonymous reviewer comments during manuscript preparation.

\section{References}

Ackerman, S. A., Strabala, K. I., Menzel, W. P., Frey, R. A., Moeller, C. C., \& Gumley, L. E. (1998). Discriminating clear sky from clouds with MODIS. Journal of Geophysical Research-Atmospheres, 103, 32141-32157.

Barnett, T. P., Adam, J. C., \& Lettenmaier, D. P. (2005). Potential impacts of a warming climate on water availability in snow-dominated regions. Nature, 438, 303-309.

Barry, R. G. (2002). The role of snow and ice in the global climate system: A review. Polar Geography, 26, 235-246.

Brown, R. D., \& Robinson, D. A. (2011). Northern Hemisphere spring snow cover variablity and change over 1922-2010 including an assessment of uncertainty. The Cryosphere, 5, 219-229.

Cayan, D. R. (1996). Interannual climate variability and snowpack in the western United States. Journal of Climate, 9, 928-948.

Cayan, D. R., Kammerdiener, S. A., Dettinger, M. D., Caprio, J. M., \& Peterson, D. H. (2001). Changes in the onset of spring in the western United States. Bulletin of the American Meteorological Society, 82, 399-415.

Chander, G., \& Markham, B. (2003). Revised Landsat-5 TM radiometric calibration procedures and postcalibration dynamic ranges. IEEE Transactions on Geoscience and Remote Sensing, 41, 2674-2677.

Chander, G., Markham, B. L., \& Barsi, J. A. (2007). Revised Landsat-5 thematic mapper radiometric calibration. IEEE Geoscience and Remote Sensing Letters, 4, 490-494.

Chander, G., Markham, B. L., \& Helder, D. L. (2009). Summary of current radiometric calibration coefficients for Landsat MSS, TM, ETM +, and EO-1 ALI sensors. Remote Sensing of Environment, 113, 893-903.

Chatfield, C. (2004). The analysis of time series, an introduction (6th ed.). New York: Chapman and Hall/CRC.

Chavez, P. S. (1996). Image-based atmospheric corrections revisited and improved. Photogrammetric Engineering and Remote Sensing, 62, 1025-1036.

Conover, W. (1980). Practical nonparameteric statistics (2nd ed.). New York: John Wiley and Sons.

Coppin, P. R., \& Bauer, M. E. (1994). Processing of multitemporal Landsat TM imagery to optimize extraction of forest cover change features. IEEE Transactions on Geoscience and Remote Sensing, 32, 918-927.

Derksen, C. \& Brown, R. (2012). Spring snow cover extent reductions in the 2008-2012 period exceeding climate model projections. Geophysical Research Letters, 39.

Dozier, J. (1984). Snow reflectance from Landsat-4 Thematic Mapper. IEEE Transactions on Geoscience and Remote Sensing, 22, 323-328.

Dozier, J. (1989). Spectral signature of alpine snow cover from the Landsat Thematic Mapper. Remote Sensing of Environment, 28, 9-22.

Dozier, J., \& Frew, J. (1990). Rapid calculation of terrain parameters for radiation modeling from digital elevation data. IEEE Transactions on Geoscience and Remote Sensing, 28, 963-969.

Dozier, J., \& Frew, J. (2009). Computational provenance in hydrologic science: A snow mapping example. Philosophical Transactions of the Royal Society a-Mathematical Physical and Engineering Sciences, 367, 1021-1033.

Dozier, J., \& Painter, T. H. (2004). Multispectral and hyperspectral remote sensing of alpine snow properties. Annual Review of Earth and Planetary Sciences, 32, 465-494.

Feng, M., Huang, C. Q., Channan, S., Vermote, E. F., Masek, J. G., \& Townshend, J. R. (2012). Quality assessment of Landsat surface reflectance products using MODIS data. Computers and Geosciences, 38, 9-22.

Hagolle, O., Huc, M., Pascual, D. V., \& Dedieu, G. (2010). A multi-temporal method for cloud detection, applied to FORMOSAT-2, VEN mu S, LANDSAT and SENTINEL-2 images. Remote Sensing of Environment, 114, 1747-1755.

Hall, D. K., Foster, J. L., Salomonson, V. V., Klein, A. G., \& Chien, J. Y. L. (2001). Development of a technique to assess snow-cover mapping errors from space. IEEE Transactions on Geoscience and Remote Sensing, 39, 432-438. 
Hall, D. K., Foster, J. L., Verbyla, D. L., Klein, A. G., \& Benson, C. S. (1998). Assessment of snow-cover mapping accuracy in a variety of vegetation-cover densities in central Alaska. Remote Sensing of Environment, 66, 129-137.

Hall, D. K., Kelly, R. E. J., Riggs, G. A., Chang, A. T. C., \& Foster, J. L. (2002b). Assessment of the relative accuracy of hemispheric-scale snow-cover maps. In J. G. Winther, \& R. Solberg (Eds.), Annals of Glaciology, Vol. 34, 2002. (pp. 24-30)Cambridge: Int Glaciological Soc.

Hall, D. K., \& Martinec, J. (1985). Remote sensing of ice and snow. New York: Chapman and Hall.

Hall, D. K., \& Riggs, G. A. (2007). Accuracy assessment of the MODIS snow products. Hydrological Processes, 21, 1534-1547.

Hall, D. K., \& Riggs, G. A. (2011). Normalized-difference snow index (NDSI), Encylopedia of Earth Sciences Series. In V. P. Singh, P. Singh, \& U. K. Haritashya (Eds.), Encylopedia of snow, ice and glaciers (pp. 780-799). : Springer.

Hall, D. K., Riggs, G. A., \& Salomonson, V. V. (1995). Development of methods for mapping global snow cover using moderate resolution imaging spectroradiometer data. Remote Sensing of Environment, 54, 127-140.

Hall, D. K., Riggs, G. A., Salomonson, V. V., DiGirolamo, N. E., \& Bayr, K. J. (2002a). MODIS snow-cover products. Remote Sensing of Environment, 83, 181-194.

Hall, D. K., Tait, A. B., Foster, J. L., Chang, A. T. C., \& Allen, M. (2000). Intercomparison of satellite-derived snow-cover maps. In K. Steffen (Ed.), Annals of glaciology, Vol 31 2000. (pp. 369-376)Cambridge: Int Glaciological Soc.

Hamlet, A. F., Mote, P. W., Clark, M. P., \& Lettenmaier, D. P. (2005). Effects of temperature and precipitation variability on snowpack trends in the western United States. Journal of Climate, 18, 4545-4561.

Huang, C. Q., Thomas, N., Goward, S. N., Masek, J. G., Zhu, Z. L., Townshend, J. R. G., et al (2010). Automated masking of cloud and cloud shadow for forest change analysis using Landsat images. International Journal of Remote Sensing, 31, 5449-5464.

Hutchison, K. D., Mahoney, R. L., Vermote, E. F., Kopp, T. J., Jackson, J. M., Sei, A., et al. (2009) A geometry-based approach to identifying cloud shadows in the VIIRS cloud mask algorithm for NPOESS. Journal of Atmospheric and Oceanic Technology, 26, 1388-1397.

Irish, R. R., Barker, J. L., Goward, S. N., \& Arvidson, T. (2006). Characterization of the Landsat-7 ETM + automated cloud-cover assessment (ACCA) algorithm. Photogrammetric Engineering and Remote Sensing, 72, 1179-1188.

Jones, P. D., \& Hulme, M. (1996). Calculating regional climatic time series for temperature and precipitation: Methods and illustrations. International Journal of Climatol ogy, 16, 361-377.

Kalnay, E., Kanamitsu, M., Kistler, R., Collins, W., Deaven, D., Gandin, L., et al. (1996). The NCEP/NCAR 40-year reanalysis project. Bulletin of the American Meteorological Society, 77, 437-471.

Kane, V. R., Gillespie, A. R., McGaughey, R., Lutz, J. A., Ceder, K., \& Franklin, J. F. (2008). Interpretation and topographic compensation of conifer canopy self-shadowing. Remote Sensing of Environment, 112, 3820-3832.

Klein, A. G., Hall, D. K., \& Riggs, G. A. (1998). Improving snow cover mapping in forests through the use of a canopy reflectance model. Hydrological Processes, 12, 1723-1744

Knowles, N., Dettinger, M. D., \& Cayan, D. R. (2006). Trends in snowfall versus rainfall in the Western United States. Journal of Climate, 19, 4545-4559.

Li, B. L., Zhu, A. X., Zhou, C. H., Zhang, Y. H., Pei, T., \& Qin, C. Z. (2008). Automatic mapping of snow cover depletion curves using optical remote sensing data under conditions of frequent cloud cover and temporary snow. Hydrological Processes, 22, 2930-2942.

Lu, D., Ge, H., He, S., Xu, A., Zhou, G., \& Du, H. (2008). Pixel-based Minnaert correction method for reducing topographic effects on a Landsat 7 ETM + image. Photogrammetric Engineering and Remote Sensing, 74, 1343-1350.

Masek, J. G., Vermote, E. F., Saleous, N. E., Wolfe, R., Hall, F. G., Huemmrich, K. F., et al. (2006). A Landsat surface reflectance dataset for North America, 1990-2000. IEEE Geoscience and Remote Sensing Letters, 3, 68-72.
Meyer, P., Itten, K. I., Kellenberger, T., Sandmeier, S., \& Sandmeier, R. (1993). Radiometric corrections of topographically induced effects on Landsat TM data in an alpine environment. ISPRS Journal of Photogrammetry and Remote Sensing, 48, 17-28.

Minder, J. R., Mote, P. W., \& Lundquist, J. D. (2010). Surface temperature lapse rates over complex terrain: Lessons from the Cascade Mountains. Journal of Geophysical Research-Atmospheres, 115.

Mitchell, J. M. (1976). The regionalization of climate in the western United States. Journal of Applied Meteorology, 15, 920-927.

Mote, P. W., Hamlet, A. F., Clark, M. P., \& Lettenmaier, D. P. (2005). Declining mountain snowpack in western north America. Bulletin of the American Meteorological Society, $86,39-49$.

Peterson, T. C., Easterling D. R., Karl, T. R., Groisman, P., Nicholls, N., Plummer, N., et al. (1998). Homogeneity adjustments of in situ atmospheric climate data: A review. International Journal of Climatology, 18, 1493-1517.

Pierce, D. W., Barnett, T. P., Hidalgo, H. G., Das, T., Bonfils, C., Santer, B. D., et al. (2008). Attribution of declining Western US snowpack to human effects. Journal of Climate, $21,6425-6444$

Riggs, G. A., Hall, D. K., \& Salomonson, V. V. (2006). MODIS snow products user guide to collection 5.

Rittger, K., Painter, T. H., \& Dozier, J. (2012). Assessment of methods for mapping snow cover from MODIS. Advances in Water Resources, 51, 367-380.

Rosenthal, W., \& Dozier, J. (1996). Automated mapping of montane snow cover at subpixel resolution from the Landsat Thematic Mapper. Water Resources Research, 32, 115-130.

Salomonson, V. V., \& Appel, I. (2004). Estimating fractional snow cover from MODIS using the normalized difference snow index. Remote Sensing of Environment, 89, $351-360$

Seidel, K., Ade, F., \& Lichtenegger, J. (1983). Augmenting LANDSAT MSS data with topographic information for enhanced registration and classification. IEEE Transactions on Geoscience and Remote Sensing, 21, 252-258.

Seidel, K., \& Martinec, J. (2004). Remote sensing in snow hydrology runoff modeling, effect of climate change. Chichester, UK: Praxis Publishing.

Serreze, M. C., Clark, M. P., Armstrong, R. L., McGinnis, D. A., \& Pulwarty, R. S. (1999). Characteristics of the western United States snowpack from snowpack telemetry (SNOTEL) data. Water Resources Research, 35, 2145-2160.

Smith, J. A., Lin, T. L., \& Ranson, K. J. (1980). The Lambertian assumption and Landsat data. Photogrammetric Engineering and Remote Sensing, 46, 1183-1189.

Song, C., Woodcock, C. E., Seto, K. C., Lenney, M. P., \& Macomber, S. A. (2001). Classification and change detection using Landsat TM data: When and how to correct atmospheric effects? Remote Sensing of Environment, 75, 230-244.

Teillet, P. M., Guindon, B., \& Goodenough, D. G. (1982). On the slope-aspect correction of multispectral scanner data. Canadian Journal of Remote Sensing, 8, 84-106.

Vermote, E. F., \& Kotchenova, S. (2008). Atmospheric correction for the monitoring of land surfaces. Journal of Geophysical Research-Atmospheres, 113.

Vermote, E. F. Tanre, D., Deuze, J. L. Herman, M. \& Morcrette, J. J. (1997). Second simulation of the satellite signal in the solar spectrum, 6S: An overview. IEEE Transactions on Geoscience and Remote Sensing, 35, 675-686.

Warren, S. G. (1982). Optical-properties of snow. Reviews of Geophysics, 20, 67-89.

Westerling, A. L., Hidalgo, H. G., Cayan, D. R., \& Swetnam, T. W. (2006). Warming and earlier spring increase western US forest wildfire activity. Science, 313, 940-943.

Winther, J. G., \& Hall, D. K. (1999). Satellite-derived snow coverage related to hydropower production in Norway: Present and future. International Journal of Remote Sensing, 20, 2991-3008.

Wiscombe, W. J., \& Warren, S. G. (1980). A model for the spectral albedo of snow. 1. Pure snow. Journal of the Atmospheric Sciences, 37, 2712-2733. 